\title{
Caso 3-2015: Masculino 19 años con neumorraquis post-traumático
}

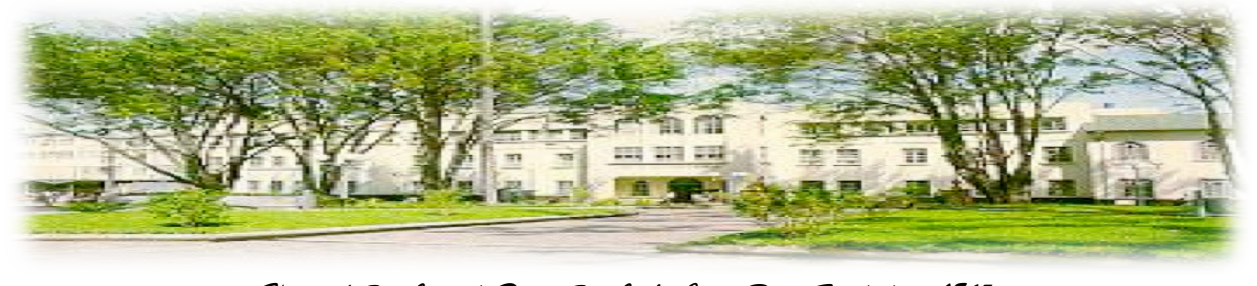

Haspital San quan de Dias. San Masé. Casta Rica. Fundada en 1845

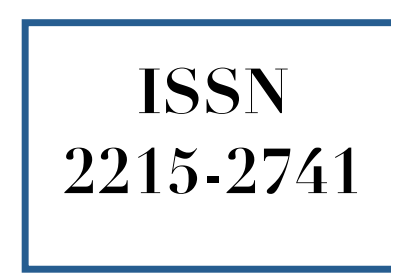

\section{Reporte de Caso}

Recibido: $\quad 02 / 09 / 2014$

Aceptado: $\quad$ 28/11/2014

Donato Salas Segura ${ }^{1}$

${ }^{1}$ Médico Especialista en Medicina Interna y Medicina Crítica y Cuidado Intensivo. Universidad de Costa Rica. Unidad de Cuidados Intensivos. Hospital Dr. Rafael Ángel Calderón Guardia. Correo electrónico: donato.salas@ucr.ac.cr

\section{RESUMEN}

Neumorraquis es la presencia de aire en el espacio epidural, subdural o subaracnoideo y tiene varias etiologías. Usualmente es asintomático y es un hallazgo casual en los estudios radiológicos. Se reporta un caso de neumorraquis en un paciente con traumas múltiples, que simuló un cuadro de meningitis.

\section{PALABRAS CLAVE}

Neumorraquis; espacio epidural; trauma.

\section{ABSTRACT}

Pneumorrhachis, the presence of air in the epidural, subdural, or subarachnoid space, has several etiologies. It is usually asymptomatic and is an incidental finding on imaging studies. We report a case of pneumorrhachis in a patient with multiple injuries that simulated meningitis.

\section{KEY WORDS}

Pneumorrhachis; epidural space; trauma.

\section{CASO CLÍNICO}

Se trató de un paciente masculino de 19 años de edad, conocido sano, taxista, quien sufrió un accidente de tránsito al ser arrollado por un vehículo automotor, el cual le produjo trauma moderado de cráneo, trauma cerrado de abdomen, fracturas vertebrales de T12 a L3 y de fémur izquierdo.

En el día 13 de su evolución intrahospitalaria, presentó fiebre y alteración de la conciencia con rigidez nucal, ictericia y un abdomen doloroso por lo cual se le realizó una tomografía abdomino-pélvica. Ésta no demostró lesiones intrabdominales pero halló una fractura de sacro inadvertida hasta ese momento y visualizó gas dentro del canal raquídeo (figura 1).

A pesar de los hallazgos radiológicos, se le practicó una laparotomía exploratoria por la sospecha de perforación de recto, pero que no se encontró mayores lesiones intrabdominales y se le tomó una biopsia en cuña de hígado por la ictericia.

Descartada la lesión abdominal, se sospechó meningitis bacteriana y fue trasladado a la Unidad de Cuidado Intensivo para su vigilancia y manejo. La punción lumbar encontró un 
líquido cefalorraquídeo hemorrágico que no cultivó ningún patógeno.

Su evolución clínica fue satisfactoria, con resolución del síndrome de respuesta inflamatoria sistémica, el trauma de cráneo, la alteración del estado de conciencia y la fractura de fémur que recibió osteosíntesis. El patrón de bilirrubinas era de tipo colestásico y eso fue confirmado por la biopsia de hígado que mostró colestasis sin lesión hepatocelular, concluyéndose que la misma era secundaria a medicamentos.

El neumorraquis y las fracturas vertebrales y sacras recibieron un tratamiento conservador.

El paciente tuvo una adecuada evolución clínica y se egresó de la Unidad de Cuidados Intensivos en buen estado general, para que continuara rehabilitación física en otro centro médico.

\section{DISCUSIÓN Y ANÁLISIS DEL CASO}

\section{Introducción}

El neumorraquis es la presencia de aire en el canal medular y es un hallazgo radiológico conspicuo pero raro ${ }^{(1)}$, cuya presencia es casi siempre asintomática pero que está asociada a condiciones severas como trauma o estado asmático.

En este trabajo se presenta un caso de neumorraquis en un paciente politraumatizado $y$ en el cual se presentó con alteración de la conciencia y meningismo.

\section{Discusión}

El neumorraquis recibe varios otros nombres como neumocele intraespinal, neumatosis espinal, subdural o subaracnoidea; enfisema espinal o enfisema epidural ${ }^{(2)} \mathrm{y}$ originalmente fue descrito en $1977^{(3)}$. Puede tener una localización epidural o subdural, e incluso subaracnoidea. Esta última localización es frecuentemente secundaria a traumas mayores. Ha sido asociado no solamente con trauma, sino también con aire en otras cavidades (neumotórax, neumomediastino) y entre las etiologías que lo ocasionan, se mencionan condiciones respiratorias que producen altas presiones intratorácicas y barotrauma, como lo pueden ser el asma bronquial y la tos violenta, o las compresiones torácicas durante las maniobras de resucitación. Puede ser iatrogénico después de cirugía de columna vertebral, procedimientos diagnósticos como la punción lumbar o anestesia raquídea.
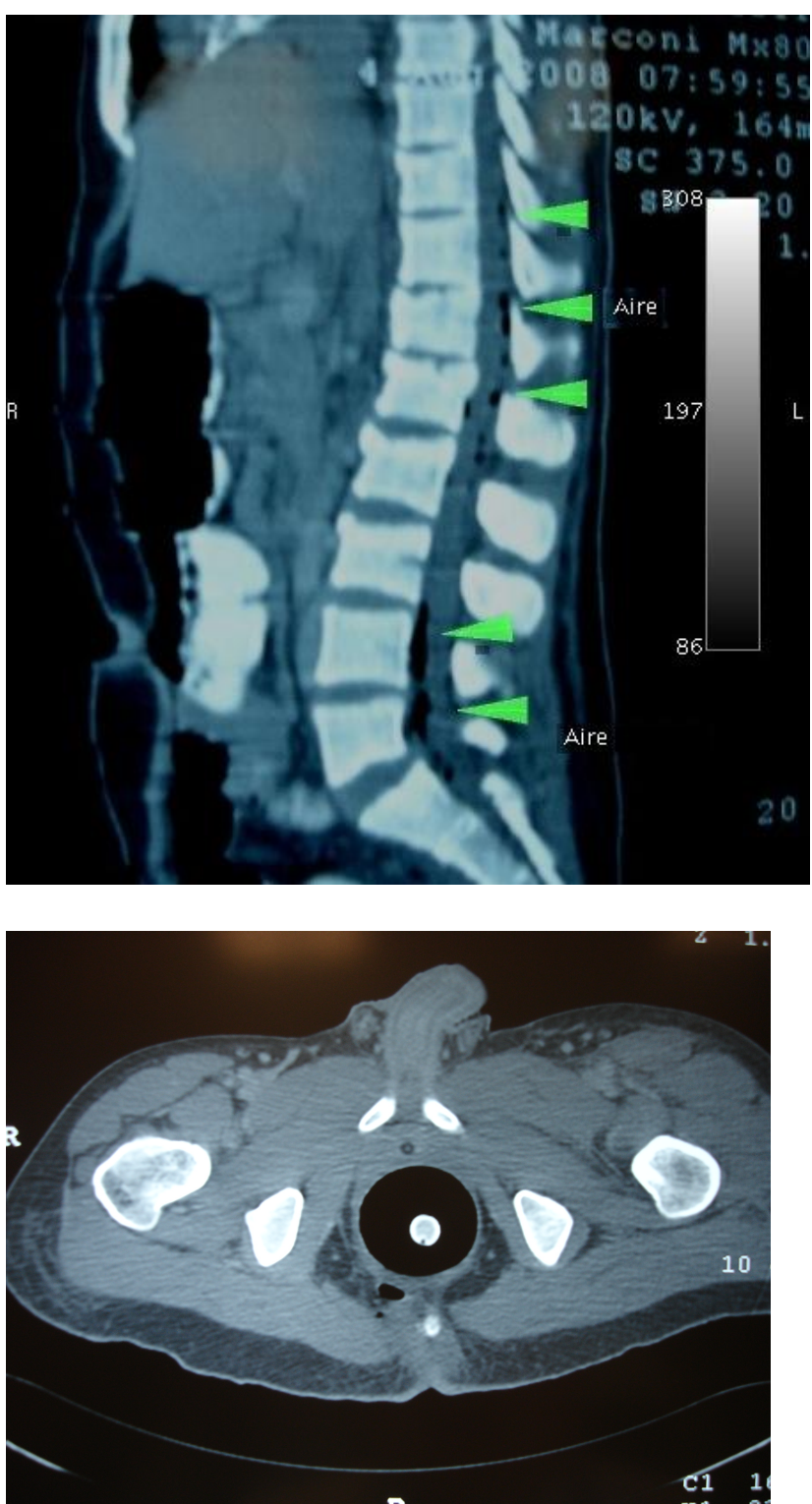

Figura 1. Cortes tomográficos del paciente. En la foto superior se puede apreciar las múltiples burbujas de aire en el canal espinal que se extienden desde T10 hasta L5, asimismo pueden observarse las fracturas de los cuerpos vertebrales de T12 a L3. En la foto inferior se observa la gran cantidad de aire a nivel del filum terminal en los cortes a nivel pélvico.

El aire puede entrar al canal raquídeo por vía directa, como ocurriría en el trauma espinal penetrante o por una vía indirecta, por medio de un mecanismo de válvula unidireccional, disecando a través de los tejidos blandos paraespinales, hasta alcanzar el foramen neural y de allí el canal espinal ${ }^{(3)}$.

El diagnóstico de neumorraquis es 
habitualmente circunstancial, cuando se observa el aire en algún estudio de imagen ya sean radiografías, tomografía axial computadorizada o resonancia magnética nuclear. Aunque se considera que en la mayoría de los casos es asintomático, puede producir meningismo e incluso alteración de la conciencia ${ }^{(4)}$, como efectivamente ocurrió en este caso.

El manejo es usualmente conservador, aunque si se asocia a neumoencéfalo puede requerir de descompresión quirúrgica. En la mayoría de los casos, el tratamiento irá dirigido a la etiología causal y no al neumorraquis mismo ${ }^{(3,5)}$.

\section{BIBLIOGRAFÍA}

1. Newbold RG Wienner MD Volger JB Martinez S. Traumatic pneumorrhachis. Am J Roentgenol. 1987;148:615-616.

2. Gosh BKP Yeo AWY. Traumatic pneumorrahachis. J Trauma 2005;8:875-879.

3. Oertel MF Korint MC Reinges MHT Krings T Terbeck S Gilsbacch JM. Pathogenesis, diagnosis and management of pneumorrahachis. Eur Spine J 2006;15(5):S636-S643.

4. De Oliveira G Charchaflieh J Walega D. Pneumorrhachis mimicking meningitis after a paramedian lumbar interlaminar injection. Clin J Pain. 2011;27(4):355-356.

5. Gosh BKP Hoe MNY. Traumatic epidural emphysema. Spine. 2004;29(22):S528S530.

\section{FUENTES DE APOYO}

No hay fuentes de apoyo que declarar.

\section{CONFLICTO DE INTERÉS}

El autor declara que en el presente reporte no hubo ningún conflicto de interés. 